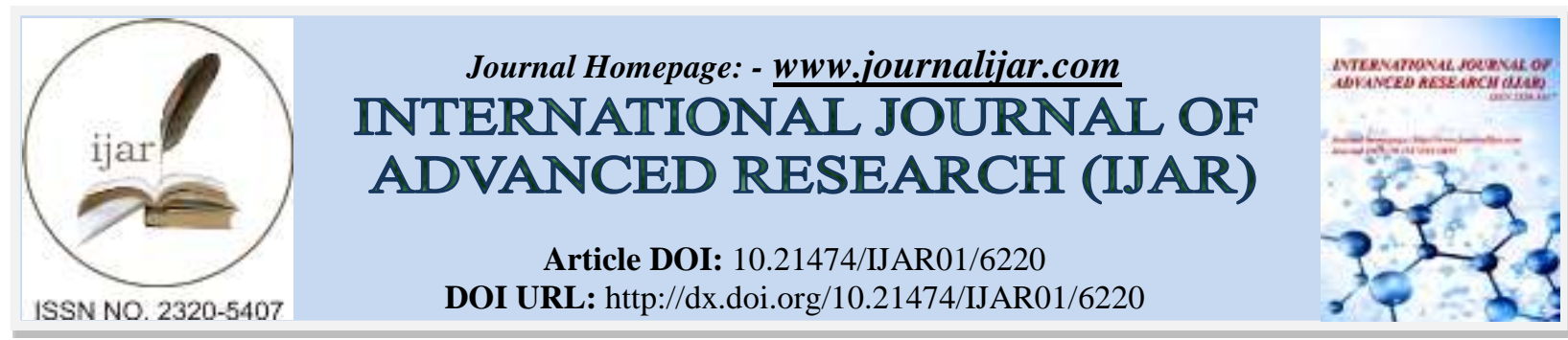

RESEARCH ARTICLE

\title{
INVESTIGATION OF C. LONGA LEAVES FOR IMMUNOMODULATION: A PRELIMINARY STUDY.
}

\author{
Shikha Rana ${ }^{1}$ and Dr. Savita Dixit ${ }^{2}$. \\ 1. Research Scholar, (Corresponding Author), Maulana Azad National Institute of Technology, Bhopal. \\ 2. Professor, Head, Deptt. Of Chemistry, Maulana Azad National Institute of Technology, Bhopal.
}

\section{Manuscript Info}

Manuscript History

Received: 05 November 2017

Final Accepted: 07 December 2017

Published: January 2018

Key words:-

Immunomodulation; C. longa leaves;

Antioxidant activity; Antimicrobial activity; phytochemicals.

\begin{abstract}
Turmeric (Curcuma longa) is a small rhizomatous perennial herb belonging to Zingiberaceae family originating mostly from India. The rhizome has been used widely as a spice, colouring agent and for various therapeutic properties. The leaves of $\mathrm{C}$. longa plant are less explored though they possess therapeutic properties. Aim: Present study was carried out to verify the immunomodulation activity in the methanolic extract of C. longa leaves. Method: Various phytochemicals have been evaluated by the standard methods proposed by Harborne. The antioxidant activity was investigated by DPPH radical scavenging activity, NO scavenging activity and Total antioxidant activity. The antimicrobial activity was investigated by disc diffusion method. Result: The proper working of the immune cells depends on the balance of the antioxidant-oxidant balance. The investigations thus carried out suggested that $\mathrm{C}$. longa leaves is a reliable source of antioxidants and is an excellent antimicrobial agent. The phytochemicals are in abundance in the leaf extracts which supports the antioxidant and antimicrobial properties. Conclusion: The antioxidants and antimicrobial activity are key to the proper functioning of the immune cells and the results clearly suggest that $\mathrm{C}$. longa leaves possess decent antioxidant and antimicrobial activity thus, suggesting that C. longa leaves are potent immunomodulator.
\end{abstract}

Copy Right, IJAR, 2018,. All rights reserved.

\section{Introduction:-}

The natural defence system against various infectious diseases is known as the immunity of the body. There are several factors which can bring about immunity such as immunization, previous infection and other external stimuli [1]. The immune response integrates concerted and coordinated response of specific cells and mediators against foreign particles as immunity is adept to distinguish among body's own cells and foreign particles [1]. Broadly immune system has been categorised into innate immune system (nonspecific) and adaptive immune system (specific) [2]. The immune system is responsible for maintaining the homeostasis within the body and is affected by certain exogenous and endogenous factors leading to immunostimulation. Such immunostimulations can be normalised or modulated by immunomodulators [3].

In the last 25 years, the frequency of life threatening infections has increased dramatically among various patients and especially those receiving broad spectrum antibiotics, corticosteroids, and cytotoxic drugs [4]. To further complicate matters, there has been an upsurge in the number of strains of infectious agents that no longer succumb 
to antibiotics in the last two decades. It is apparently clear that, antibiotics have lost their magic touch after decades of incautious prescription, improper use and inevitable spread of bacterial genes that confer drug resistance [5]. In the old days, scientists concentrated on looking for antimicrobials mainly in organisms from soil but today researchers have broadened their search. In many laboratories, the break with tradition has even been greater. Instead of focusing on drugs that block bacterial growth, researchers have been trying to develop carbohydrate or protein molecules that can boost people's natural defences against microbes [6]. This immunological approach has been postulated as the most probable way to deal with small pockets of resistant bacteria that survive antibiotic treatment. Thus, designing and development of drug candidates from various conventional or complementary and alternative medicines has gained interest. Due to the occurrence of chemical drugs-related adverse effects, natural drugs are the potential agents to replace the synthetic drugs in therapeutic regimens.

In the past 50 years the infectious diseases have included those which are predominantly caused by microbes in immunocompromised individuals. The limited efficacy of the antimicrobial agents along with increasing resistance to such agents has evolved an urgent need for new therapies against infectious diseases and immunomodulation is one such approach [7]. Immunomodulation using plants, or its products has become an accepted therapeutic approach.

Immunomodulation can serve as an alternative to conventional methods of therapeutics for several diseased conditions such as when the patient's defence mechanism has to be stimulated in conditions such as flawed immune responsiveness or in conditions such as low haemoglobin count, inflammatory diseases auto immune disorders etc [8]. Many plants have been claimed to possess immunomodulatory activities such as Withania somnifera, Tinospora cordifolia and Mangifera indica [9-10].

Curcuma genus (zingiberaceae family) contains more than 80 species. Turmeric (Curcuma longa L.) is a therapeutic plant [11]. India is the largest producer or turmeric plants. The rhizomes are mostly used, and leaves are not given care. The leaves of turmeric, known as Haldi leaves are used in Indian and Malaysian cookery as both fresh and dried-extracted form. It is also a good colouring agent and a basic ingredient in curry powders and are purported to improve digestion and reduce gas and bloating [12].

Many studies have been conducted on the rhizome of curcuma longa. It has also been reported that rhizomes of curcuma longa (turmeric) shows antioxidant, anti-inflammatory, insect antifeedant, antiviral, cytotoxic and trypanocidal activities and is effective in the treatment of Alzheimer's disease, cancer, arthritis, and other clinical disorders [13].

The experiment performed by Yunbao Liu et.al shows that leaf constituents of C. longa contains 8,12epoxygermacra- 1, 4,7,11-tetraen-6-one; 8,12-epoxygermacra-1; 4,7,11-tetraene; cyclohexanecarboxylic acid methyl ester; isopulegol ; 2-menthen-1-ol ; menth-1-en-9-ol; octahydrocurcumin; labda-8(17)-12-diene-15, 16-dial; and coronadiene. But the antioxidant, antimicrobial and immunomodulatory activities of leaf constituents of these plants are not in the literature. Presently the antioxidant and antimicrobial activity are studies are carried out for C. longa leaves to verify its immunomodulating properties.

\section{Materials and Method:-}

\subsection{Sample Preparation}

The leaves of C. longa were collected from Naya Nangal, Punjab. These leaves were then identified Dr Abhishek Gupta, Director, CMBT, Bhopal. These leaves were then washed and the disinfected. These leaves were the shade dried for 2 weeks and then grinded in the grinder. After grinding this powder was then extracted using 70:30 methanol and water as solvent. The process runs until the extraction is complete. This process was done in accordance to [14].

\subsection{Total Phenolic Content}

$\mathrm{ml}$ of sample was mixed with $1.0 \mathrm{ml}$ of Folin and Ciocalteu's phenol reagent. After $3 \mathrm{~min}, 1.0 \mathrm{ml}$ of saturated $\mathrm{Na}_{2} \mathrm{CO}_{3}(\sim 35 \%)$ was added to 23 the mixture and made up to $10 \mathrm{ml}$ by adding distilled water. The reaction was kept in the dark for $90 \mathrm{~min}$, observed under UV-Vis spectrophotometer at $760 \mathrm{~nm}$ absorbance. Gallic acid was used as a standard with varied concentration from $200 \mathrm{ppm}$ to $1000 \mathrm{ppm}$. A calibration curve was constructed with different concentrations of tannic acid (0.02- $0.1 \mathrm{mM})$ as standard. The results were expressed as $\mathrm{mg}$ of catechol equivalents/g of extract [15]. 


\subsection{Total Flavonoid Content}

A clean test tube was taken and $0.5 \mathrm{ml}$ of the sample (Extract) is added, containing $1.25 \mathrm{ml}$ of distilled water. Then $0.075 \mathrm{ml}$ of $5 \%$ sodium nitrite solution is added and allowed to stand for $5 \mathrm{~min}$. $0.15 \mathrm{ml}$ of $10 \%$ aluminium chloride is added, after $6 \mathrm{~min} 0.5 \mathrm{ml}$ of $1.0 \mathrm{M}$ sodium hydroxide was added and the mixture were diluted with another $0.275 \mathrm{ml}$ of distilled water. The absorbance of the mixture at $510 \mathrm{~nm}$ was measured immediately. The flavonoid content was expressed as mg querecitin equivalents /g sample.

\subsection{Phytochemical Screening}

Phytochemical screening for the presence of major types of compounds present in the extract was done by standard methods developed by Harbone [16].

\subsection{Antioxidant Properties \\ 1.5.1 DPPH Free Radical Scavenging Activity}

The free radical scavenging activities of the extracts were determined by using 2, 2- Diphenyl-1-picrylhydrazyl (DPPH) free radical scavenging method [17]. DPPH in oxidized form gives a deep violet color in methanol. The antioxidant activity using the DPPH (1, 1-diphenyl-2-Picrylhydrazyl) assay was assessed by this method. The sample extracts and standards (BHA and ascorbic acid) were prepared at various concentrations (200-1000 ppm) and mixed with ethanolic solution of DPPH with a concentration of $0.04 \mathrm{mg} / \mathrm{ml}$. After stand for 20 min in the dark, the mixtures were measured at $517 \mathrm{~nm}$ against ethanol as blank using UV-Vis Spectrophotometer.

The percentage inhibition of DPPH by extracts was calculated by using following formula

$$
\text { Scavenging Activity }(\%)=\quad \frac{(\text { Abs Control }- \text { Abs Sample })}{\text { Abs Control X } 100} \quad \text {---------1.5.1.1 }
$$

\subsubsection{Nitric oxide radical scavenging activity}

Plant extract was dissolved in distilled water for this quantification. Sodium Nitroprusside (5 mM) in standard phosphate buffer saline $(0.025 \mathrm{~m}, \mathrm{pH} 7.4)$ was incubated with different concentration $(100-400 \mu \mathrm{g} / \mathrm{ml}) \mathrm{of}$ methanol extract and tubes were incubated at $29^{\circ} \mathrm{C}$ for 3 hours. Control experiment without the test compounds but with equivalent amount of buffer was conducted in an identical manner. After 3 hours, incubated samples were diluted with $1 \mathrm{ml}$ of Griess reagents. The absorbance of the colour developed during diazotization of Nitrite with sulphanilamide and its subsequent coupling with Napthylethylenediamine hydro-chloride was observed at 550nm on spectrophotometer. Same procedure was done with ascorbic acid which was standard in comparison to methanol extract. Calculated the \% inhibition by formula and plot graph in compared to standard.

$$
\text { Nitric Oxide }(\%)=\quad \frac{\left(\mathrm{A}_{\text {control }}-\mathrm{A}_{\text {test }}\right)_{\mathrm{X}}}{\mathrm{A}_{\text {control }}} 100
$$

Where,

$\mathrm{A}_{\text {control }}=$ Absorbance of control reaction

$\mathrm{A}_{\text {test }}=$ Absorbance in the presence of the samples of extract.

1.5.3 Total Antioxidant Activity

Determination of total antioxidant capacity was evaluated by the Phosphomolybdenum method [18].0.3 ml of extract and sub-fraction in ethanol, ascorbic acid used as standard (5to $200 \mathrm{~g} / \mathrm{ml}$ ) and blank (ethanol) were combined with $3 \mathrm{ml}$ of reagent mixture separately and incubated at $95^{\circ} \mathrm{C}$ for $90 \mathrm{~min}$. After cooling to room temperature, the absorbance of each sample was measured at $695 \mathrm{~nm}$ against the blank. Ascorbic acid was used as standard and the total antioxidant capacity is expressed as equivalents of ascorbic acid or Gallic acid. The antioxidant activity is expressed as the number of equivalents of ascorbic acid and was calculated by the following equation:

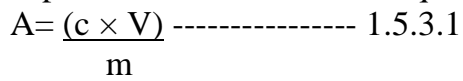

Where,

$\mathrm{A}=$ total content of antioxidant compounds, mg/g plant extract, in Ascorbic Acid Equivalent, $\mathrm{c}=$ the concentration of Ascorbic acid established from the calibration curve, $\mathrm{mg} / \mathrm{ml}$,

$\mathrm{V}=$ the volume of extract $(\mathrm{ml})$, and $\mathrm{m}=$ the weight of crude plant extract $(\mathrm{g})$

\subsection{Antimicrobial Properties}

Here agar disk diffusion method is used to test the antimicrobial activity. This method was developed in 1940 [19]. Many accepted and approved standards are published by the Clinical and Laboratory Standard Institute (CLSI) yet this method is the most efficient for testing various microorganisms using specific culture media, incubation condition and interpretive criteria of inhibition zones [20]. 
Presently agar plates are inoculated with a standardized inoculum of the test microorganism. Then, filter paper discs (about $6 \mathrm{~mm}$ in diameter), containing the test compound at a desired concentration, are placed on the agar surface. The Petri dishes are incubated under suitable conditions. Generally, antimicrobial agent diffuses into the agar and inhibits germination and growth of the test microorganism and then the diameters of inhibition growth zones are measured [21].

Based on the various literature review following 2 gram positive and 2 gram negative bacteria are tested by agar diffusion method.

1. Bacillus subtilis

2. S. auerus

3. P. aeruginosa

4. E. coli

\section{Method:-}

Overnight culture in liquid broth was grown. O.D at $660 \mathrm{~nm}$ up to $\left(1 \times 10^{6}\right)$ was maintained. The culture was spread on NAM agar medium. The $6 \mathrm{~mm}$ whattman filter paper were placed on disc of different conc of plant extract 75 $\mathrm{mg} / \mathrm{ml}$ dilution $(25,50,75,100 \%)$. Incubated at $37^{\circ} \mathrm{C}$ for $8 \mathrm{hr}$. The zone of inhibition in mm by zonal scale (HiMedia) was measured

\section{Results:-}

In the present study, the methanolic extract of turmeric leaves was screened for the presence of bioactive compounds. the results showed the presence of carbohydrates, steroids, proteins, alkaloids, tannic acid and phenolic compounds, chlorides, flavonoids and chlorides. But sulphates were absent in the methanolic extract.

\begin{tabular}{|l|l|l|}
\hline S.No. & Phytochemical Test & Curcuma Longa Leaves Extract \\
\hline 1. & Molish Test & $+\mathrm{ve}$ \\
\hline 2. & Salkoviski Test & $+\mathrm{ve}$ \\
\hline 3. & Flavonoid Test & $+\mathrm{ve}$ \\
\hline 4. & Millons Test & $+\mathrm{ve}$ \\
\hline 5. & Mayers Test & $+\mathrm{ve}$ \\
\hline 6. & Wagners Test & $+\mathrm{ve}$ \\
\hline 7. & Tannic acid and Phenolic Test & $+\mathrm{ve}$ \\
\hline 8. & Sulphate Test & -ve \\
\hline 9. & Chloride Test & $+\mathrm{ve}$ \\
\hline 10. & Saponin Test & $+\mathrm{ve}$ \\
\hline
\end{tabular}

Table 1:- Phytochemicals studies of methanolic extracts of C. longa leaves.

Methanolic extract of $\mathrm{C}$. longa leaves was evaluated quantitatively for the percentage composition of total phenolic and flavonoids. The total phenolic content was found to be $305.645 \mathrm{mg}$ of catechol equivalents/g of C. longa leaves. While, the total flavonoid content was found to be $68.375 \mathrm{mg}$ querecitin equivalents /g of C. longa leaves.

The antioxidant activity of $\mathrm{C}$. longa leaves was measured by the decolouration reaction between nitrogen electron (from $\mathrm{DPPH}^{+}$) and hydrogen atom of the hydroxyl group (from the antioxidant). The percentage scavenging activity of the standard ascorbic acis is found greater than the methanolic extract of C. longa leaves (Figure 1A). The scavenging activity of the extract against nitric oxide released by sodium nitroprusside was investigated with the help of standard Ascorbic acid (Figure 1B). C. longa leaves extract showed comparable inhibitory activities at all the concentrations tested and the total antioxidant activity of $\mathrm{C}$. longa leaves extract was higher as compared to the standard compound ascorbic acid used in the present study (Figure 1C). 
(A)

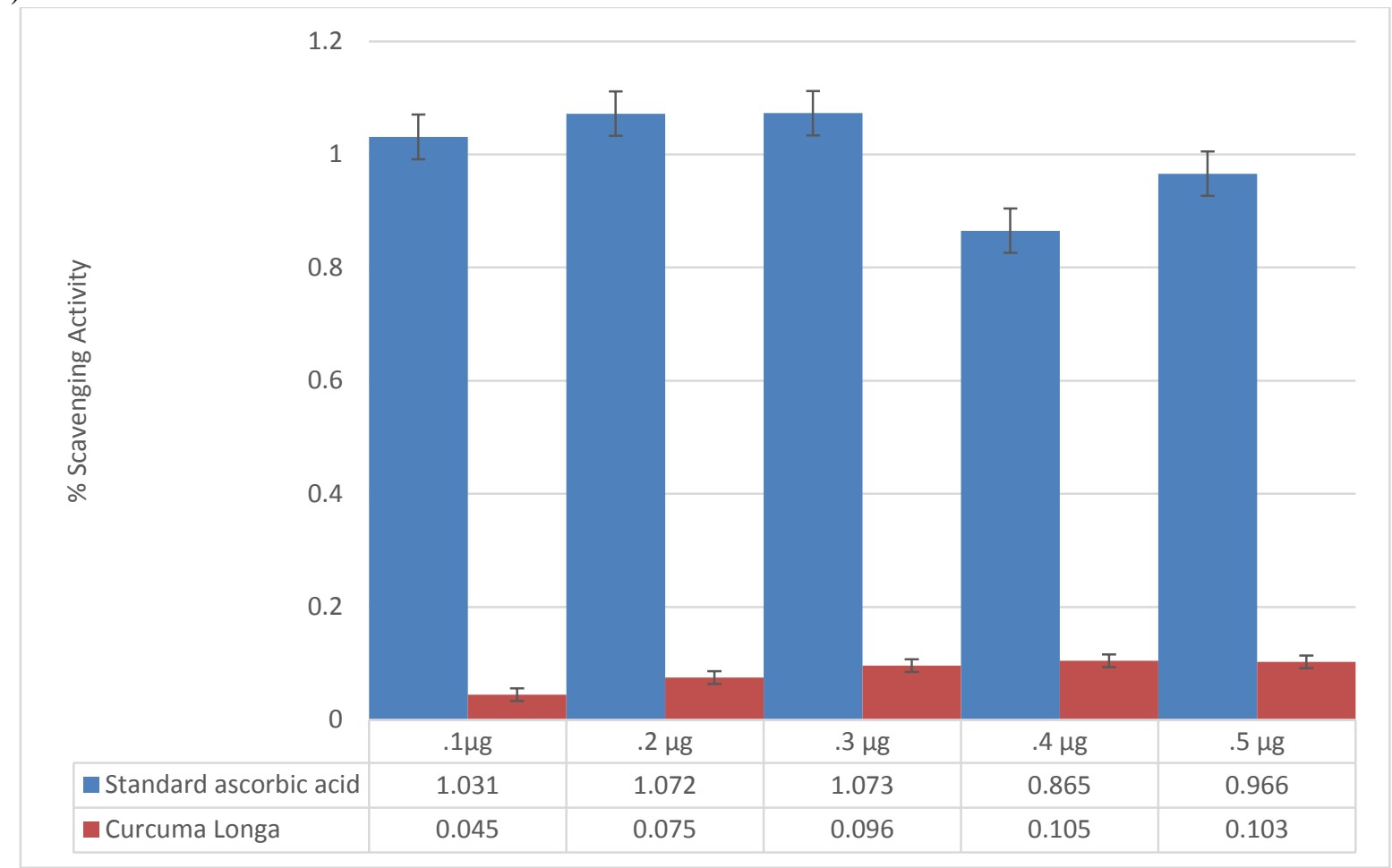

(B)

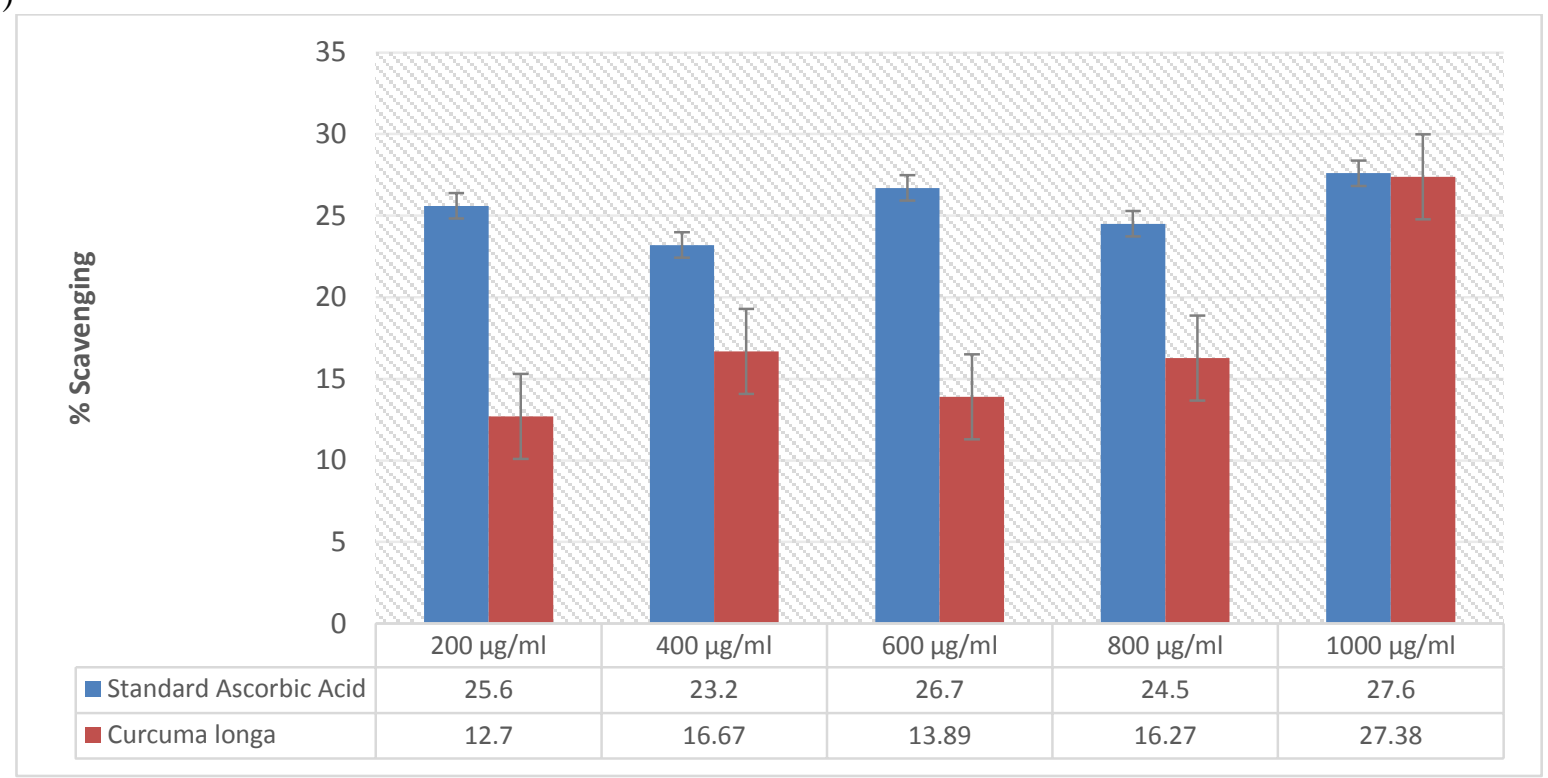


(C)

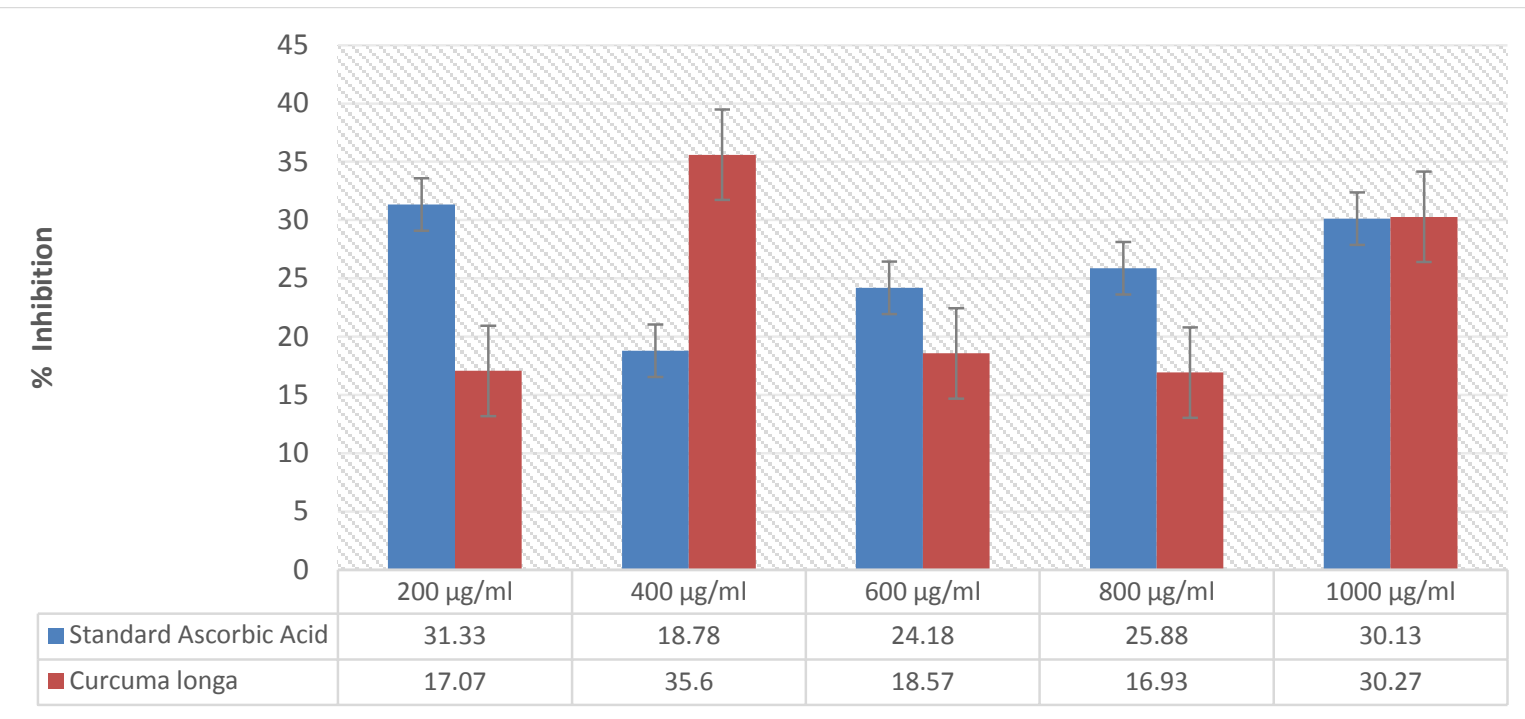

Figure 1:- (A) DPPH Free Radical Scavenging Activity; (B) Nitric oxide radical scavenging activity (C) Total Antioxidant Activity

The microbial susceptibility was collectively summarized in Figure 2. The result of antimicrobial susceptibility assay showed promising evidence for the antimicrobial effects of C. longa leaves methanolic extracts against bacterial pathogens. Methanolic extract of C. longa leaves showed that E. Coli shows maximum zone of inhibition of $14 \mathrm{~mm}$ followed by P. aeruginosa, S. aureus and B. subtilis.

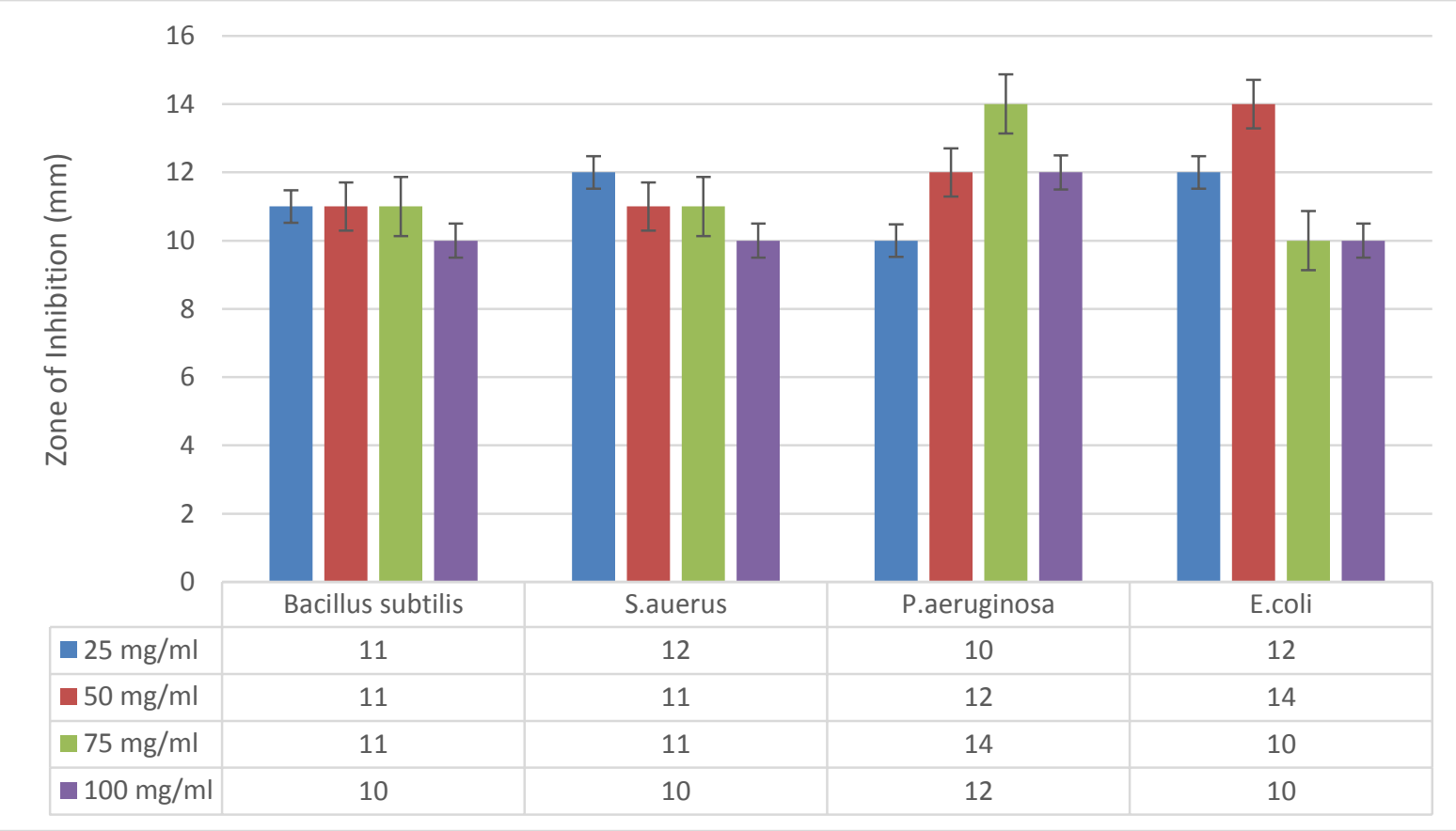

\section{Discussion:-}

Figure 2:- Antimicrobial Activity

Though conventional practices include C. longa rhizome and its powder for treating various ailments, not much scientific literature is available on the leaves of $\mathrm{C}$. longa. This signifies that a whole lot of scientific exploration needs to be done on this particular plant part of the long term used golden medicinal plant. This could further lead 
for natural alternatives for diverse diseases against synthetic drugs. Phytomedicine in the current scenario of research is gaining a lot of interest as of lesser side effects.

In case of immunodeficiency our body is unable to prevent the bogy from fighting infections and diseases. Such disorders make viral and bacterial infections easier. Many compounds derived from plants have been identified for their immunomodulatory characteristics. Use of immunomodulation as and alternative medication using plants is getting more and more attention. The isolation and discovery of immunomodulatory agents which are more specific, derived from plants, are the potent which can counteract the side effects and prohibitive costs of synthetic compounds.

The above results to the experiment shows that the methanolic extract of $\mathrm{C}$. longa leaves is a rich source of phytochemicals. Also, the phenolic compounds are much higher in concentration suggesting that this extract has strong antioxidant properties. The results are higher as compared to the ethanolic and aqueous extracts of C. longa rhizome extracts [22]. The flavonoid contents are also higher as compared to the ethanolic and aqueous extract of C. longa rhizome which suggests that $\mathrm{C}$. longa leaves have strong antioxidant properties [22].

The antioxidant studies show that the nitrous oxide scavenging activity and the total antioxidant activities of the C. longa leaves methanolic extract is comparable to the standard ascorbic acid which shows that $\mathrm{C}$. longa leaves serve as an excellent antioxidant agent. The antioxidants are the key to boost the immune system. Reactive oxygen species are formed by the immune system when acting against the external pathogens [23]. The antioxidant defences of the cells cannot counteract the excessive reactive oxygen species (ROS) and can become the source of tissue damage resulting from the oxidative stress. So normal functioning of the immune cells depends strongly on the antioxidant oxidant balance. Thus, antioxidant levels play a vital role in maintaining the adequate function of immune cells [24]. It has been found that the leaves of the plants possess more of the antimicrobial activity as compared to other parts of the plants. This is since leaves contain polyphenolic compounds in larger quantity [25]. The antimicrobial activity shows that $\mathrm{C}$. longa leaves methanolic extract have strong antimicrobial activity. This also increases with increase in concentration specially in the case of P. aeruginosa followed by S. aureus, B. subtilis and E. coli. These values are comparable to the values of $\mathrm{C}$. longa rhizome extracts. Thus, this study shows that $\mathrm{C}$. longa leaves methanolic extract has excellent antioxidant and antimicrobial properties.

\section{Conclusion:-}

The immune system defines the fight against diseases. When the antigens are over produced, the immunity gets reduced which thus requires a modulator possessing immunomodulating character. All the previous investigations have been carried out on C. longa rhizome and essential oils. These studies showed that curcumin present in the rhizome have very good antimicrobial properties but less inhibitory effects. The objective of the present study was to evaluate the turmeric leaf methanolic extracts as immunomodulating potent agent. The selection of plant part extract for screening phytochemicals, antioxidant activity and antimicrobial activity has the potential of being successful in initial steps. But therapeutic potential of this plant part should be studied more emphasizing on the immunomodulating ability. The present findings clearly suggest that $\mathrm{C}$. longa leaves possess decent antioxidant and antimicrobial activity thus, suggesting that these are potent immunomodulating agents.

\section{Conflict Of Interest:-}

The authors declare no conflict of interest.

\section{References:-}

1. Baxter D. Active and passive immunity, vaccine types, excipients and licensing. Occup. Med. $2007,57552-$ 556. 10.1093/occmed/kqm110 [PubMed].

2. Vesely M. D., Kershaw M. H., Schreiber R. D., Smyth M. J. Natural innate and adaptive immunity to cancer. Annu. Rev. Immunol. 2011, 29 235-271. 10.1146/annurev-immunol-031210-101324[PubMed].

3. Ibrahim Jantan, Waqas Ahmad, and Syed Nasir Abbas Bukhari. Plant-derived immunomodulators: an insight on their preclinical evaluation and clinical trials. Front Plant Sci. 2015; 6: 655.

4. Arokiyaraj, S., Perinbam, K., Agastian, P. and Balaraju, K. Immunosuppressive effect of medicinal plants of Kolli hills on mitogen stimulated proliferation of the human peripheral blood mononuclear cells in In vitro. Indian Journal of Pharmacology, (2007), 39 (4):180-183. 
5. Njoroge, G.N. and Bussmann, R.W. Diversity and utilization of antimalarial ethnophytotherapeutic remedies among the Kikuyus (central Kenya). Journal of Ethnobiology and Ethnomedicine, (2006), 2:8-14.

6. Kenneth Omondi Ogila, Antimicrobial and immunomodulatory properties of extracts of Asparagus setaceous Kunth and Caesalpinia volkensii Harm, 2011, Jomo Kenyatta University of Agriculture and Technology, Kenya.

7. Cordell, J. Natural products in drug discovery- Creating a new wisdom. Phytochemistiy Reviews, (2002), 1: 261 $-273$.

8. Liise-anne Pirofski and Arturo Casadevall, Immunomodulators as an antimicrobial tool, Current Opinion in Microbiology ,Volume 9, Issue 5, October 2006, Pages 489-495.

9. Makare N., Bodhankar S. and Rangari V., Immunomodulatory activity of alcoholic extract of Mangifera indica in mice, Journal of Ethnopharmacology, 2001, 78, 133-137.

10. Davis, L., Kuttan, G., Immunomodulatory activity of Withania somnifera. J. Ethnopharmacol. 2000, 71: 193200.

11. Tanzeela Nisar et.al. Turmeric: A Promising Spice for Phytochemical and Antimicrobial Activities, AmericanEurasian J. Agric. \& Environ. Sci., 2015, 15 (7): 1278-1288.

12. R. Arutselvi et.al, Phytochemical screening and comparative study of anti-microbial activity of leaves and rhizomes of turmeric varieties, Asian Journal of Plant Science and Research, 2 (2), (2012): 212-219.

13. Yunbao Liu et.al. Curcuma longa and Curcuma mangga leaves exhibit functional food property, Food Chemistry 135 (2012) 634-640.

14. J. Azmir et.al. Techniques for extraction of bioactive compounds from plant materials: A review. Journal of Food Engineering 117 (2013) 426-436.

15. Morsi RMY, Tahan NREL, El-Hadad AMA, Effect of aqueous extract Mangifera Indica leaves, as functional foods. J Appl Sci Res 6 (2010): 712.

16. Harbone JB. Phytochemical Methods- A Guide to Modern Techniques of Plant Analysis, Chapman and Hall London, 1998.

17. Brand-Williams, Cuvelier ME, Berset CLWT. Use of a free radical method to evaluate antioxidant activity. LWT-Food Science and Technology 1995; 28(1):25-30.

18. Prieto, P., Pineda, M., Aguilar, M. Spectrophotometric quantitation of antioxidant capacity through the formation of a phosphomolybdenum complex: Specific application to the determination of Vitamin E1. Anal. Biochem. 1999, 269, 337-341.

19. CLSI, Performance Standards for Antimicrobial Disk Susceptibility Tests, Approved Standard, 7th ed., CLSI document M02-A11. Clinical and Laboratory Standards Institute, 950 West Valley Road, Suite 2500, Wayne, Pennsylvania 19087, USA, 2012.

20. Mounyr Balouiri et.al. Methods for in vitro evaluating antimicrobial activity: A review. Journal of Pharmaceutical Analysis. Volume 6, Issue 2, April 2016, Pages 71-79.

21. Doughari et.al. Antimicrobial activity of leaf extracts of Senna obtusifolia (L). African Journal of Pharmacy and Pharmacology Vol. 2(1), pp. 007-013, March 2008.

22. E. M. Tanvir et.al, Antioxidant Properties of Popular Turmeric (Curcuma longa) Varieties from Bangladesh, Journal of Food $\quad$ Quality 31 May 2017, Volume 2017 (2017).

23. Fialkow L, Wang Y, Downey GP. Reactive oxygen and nitrogen species as signaling molecules regulating neutrophil function. Free Radic Biol Med. 2007; 42:153-164. doi: 10.1016/j.freeradbiomed.2006.09.030. [PubMed] [Cross Ref]

24. M De la Fuente, Effects of antioxidants on immune system ageing, European Journal of Clinical Nutrition (2002) 56, Suppl 3, S5-S8.

25. Rubilar M, Jara C, Poo Y, Acevedo F, Gutierrez C, Sineiro J, Shene C. Extracts of Maqui (Aristotelia chilensis) and Murta (Ugni molinae Turcz.): sources of antioxidant compounds and $\alpha$-Glucosidase/ $\alpha$-Amylase inhibitors. J Agric Food Chem.2011, 59:1630-1637. doi: 10.1021/jf103461k[Crossref], [PubMed], [Web of Science ®], Google Scholar. 